\title{
A Comparison of Premedication with Metoprolol, Clonidine and Tranexamic Acid and Intravenous Nitroglycerin on Intraoperative Hemodynamics and Surgical Conditions during Functional Endoscopic Sinus Surgery (Fess).
}

\author{
Shalini Bajpai ${ }^{1}$, Payal Pyati ${ }^{2}$ \\ ${ }^{1}$ Assistant Professor, Department of Anaesthesiology, GIMSR, Visakhapatnam, India \\ ${ }^{2}$ Consultant, Department of Anaesthesiology, Sunshine Hospital, Hyderabad, India.
}

\begin{abstract}
:
Background: FESS - Functional endoscopic sinus surgery, a minimally invasive surgery, has become the main stay for treatment of patients with sinus pathology. However, Intraoperative bleeding, which reduces operative field visibility is the major problem in FESS. This study compare the effects of preoperative Clonidine, Metoprolol and Tranexamic acid with Intraoperative Nitroglycerin in patients undergoing FESS on Quality of surgical field, Intraoperative blood loss, Hemodynamics and duration of surgery.

Methods: In this study 90 patients assigned to undergo FESS were randomly allocated to three groups of 30 each. Group 1 patients were premedicated orally with Metoprolol $12.5 \mathrm{mg}$ and Clonidine150mcg. Inj.Tranexamic Acid $30 \mathrm{mg} / \mathrm{kg}$ i.v. was given half an hour prior to surgery. Group II patients received NTG infusion at 2-5 mcg/kg/min, titrated to a mean arterial blood pressure of $65-75 \mathrm{~mm} / \mathrm{Hg}$. Group III underwent surgery under normotensive anesthesia.

Results: Visibility of the operative field was best in Group II when compared to Group I, which was relatively better than control group. The average blood loss and mean arterial pressure was least with Group II. Mean heart rate was significantly low in Metoprolol, Clonidine and Tranexamic acid group.

Conclusion : Nitroglycerin infusion have lesser blood loss, better quality of surgical field and reduced duration of surgery compared to premedication with Metoprolol, Clonidine and Tranexamic acid and normotensive anesthesia but in conditions where nitroglycerin infusion is contraindicated or not feasible, the use of Metoprolol, clonidine and Tranexamic acid may be an acceptable safer and simpler alternative.
\end{abstract}

Keywords: FESS, Metoprolol, Clonidine, Tranexemic acid, Nitroglycerin

\section{Introduction}

Functional endoscopic sinus surgery (FESS), a minimally invasive surgery, has become the main stay for treatment of patients with sinus pathology ${ }^{1}$. Though relatively safe, it is associated with some complications as meningitis, CSF leak, orbital and intracranial injuries, synechiae and bleeding ${ }^{2}$. Intraoperative bleeding, which reduces visibility in the operative field, is the major problem in FESS. It not only prolongs the duration of surgery but also increase the chances of complications. The complicated anatomic structure with its unique variations, the proximity of the delicate cranial base, brain, eyes, blood vessels and nerves mandates minimal bleeding, to precisely visualise the anatomy and identify the structures.

Various techniques have been utilised to minimize Intraoperative bleeding, facilitate better visualization through endoscope thus reducing complications. These include hypotensive drugs, anaesthetic agents, antifibrinolytic agents, local vasoconstrictor infiltration, anti trendelenburg position.

Intravenous Nitroglycerin, a peripheral vasodilator that causes concomitant reduction in cardiac output and systemic blood pressure is well known to reduce blood loss and improve the surgical field in FESS ${ }^{3}$. But it is used as an infusion, requires careful titration and is associated with reflex tachycardia that partly offset the beneficial effects of hypotension. So, if controlled hypotension can be provided by a relatively simpler and safer technique, the quality of surgical field can be improved.

Hence, this study was designed to compare the effects of preoperative Clonidine, Metoprolol and Tranexamic acid with Intraoperative Nitroglycerin in patients undergoing Functional Endoscopic Sinus Surgery (FESS) under General Anaesthesia (GA) on Quality of surgical field , Intraoperative blood loss , Hemodynamics - heart rate (HR) and mean arterial blood pressure (MAP) and duration of surgery.

\section{Materials And Methods}

This prospective randomised controlled clinical study was conducted after approval from ethical and scientific committee of Hospital and after detailed history, clinical examination, informed and written consent of all patients, 90 ASA I patients aged 18 to 50yrs., of either sex with pre-operative hemoglobin above $10 \mathrm{gms} / \mathrm{dl}$ 
who were to undergo FESS were included in study. Patients with hypertension, Bronchial asthma, alcohol or drug abuse, breast feeding and pregnancy, anticoagulation therapy, bleeding diathesis were excluded.

Patients were randomly allocated to three groups of 30 each; using computer generated random allocation technique. All patients were evaluated thoroughly by the anesthesiologist on the previous day of surgery. The anesthetic and surgical procedure was explained to the patient. All patients were premedicated orally with Ranitidine $150 \mathrm{mg}$ and Alprazolam $0.5 \mathrm{mg}$ HS \& 6 AM.

Group I: Oral premedication with Metoprolol $12.5 \mathrm{mg}$ (withheld if HR less than 60/min or blood pressure less than 100/60 $\mathrm{mmHg}$ ) and Clonidine 150mcg was given at night before and morning $2 \mathrm{hr}$. before surgery with sips of water.

Inj.Tranexamic Acid $30 \mathrm{mg} / \mathrm{kg}$ i.v. was given half an hour prior tosurgery.

Group II: Inj. NTG $25 \mathrm{mg} / 50 \mathrm{ml}$ normal saline infusion was started after induction at $2-5 \mathrm{mcg} / \mathrm{kg} / \mathrm{min}$ and titrated to a mean arterial blood pressure of $65-75 \mathrm{~mm} / \mathrm{Hg}$.

Group III: Normotensive anesthesia was maintained.

All patients underwent the procedure under standard general anaesthesia technique. Surgery was performed by the unit chief of the E.N.T. department. Intraoperative monitoring included electrocardiogram, noninvasive blood pressure, pulse oximetry and ETCO2.

Pre induction all patients received Inj. Glycopyrrolate $0.004 \mathrm{mg} / \mathrm{Kg}$ i.v., Inj. Fentanyl $2 \mathrm{mcg} / \mathrm{Kg}$ i.v. and Inj. Midazolam $0.03 \mathrm{mg} / \mathrm{Kg}$ i.v. Induction was done with Inj. Propofol $2 \mathrm{mg} / \mathrm{kg}$ and Inj. Vecuronium $0.1 \mathrm{mg} / \mathrm{Kg}$ i.v. and patient was intubated. Maintenance was done with Isoflurane $1 \mathrm{MAC}$, Oxygen $33 \%$ and Nitrous oxide $66 \%$. ETCO2 was maintained $35 \pm 2 \mathrm{mmHg}$.. All patients were placed in $15^{\circ}$ reverse trendelenburg position.

After induction nasal mucosa was infiltrated with $2 \mathrm{ml}$ of $2 \%$ lignocaine with adrenaline $(1: 200,000)$. If mean arterial pressure (MAP) decreased to less than $50 \mathrm{~mm} \mathrm{Hg}$, ephedrine in increments of $6 \mathrm{mg}$ i.v. was given and patient was excluded from the study.

Surgeons were blinded to the groups and were questioned about the quality of the surgical field every 15 minutes and graded according to the score proposed by FROMM and BOEZART ${ }^{4}$ (Table 1).

Table 1

\begin{tabular}{|c|l|}
\hline Grade & \multicolumn{1}{|c|}{ Assessment } \\
\hline 0 & No bleeding \\
\hline 1 & Slight bleeding- no suctioning required \\
\hline 2 & Slight bleeding - occasional suctioning required \\
\hline 3 & Slight bleeding - frequent suctioning required. Bleeding threatens surgical field a few seconds after suction is removed. \\
\hline 4 & Moderate bleeding - frequent suctioning required and bleeding threatens surgical field directly after suction is removed. \\
\hline 5 & $\begin{array}{l}\text { Severe bleeding - constant suctioning required. Bleeding appears faster than can be removed by suction. Surgical field } \\
\text { severely threatened and surgery usually not possible. }\end{array}$ \\
\hline
\end{tabular}

Blood loss was assessed by weighing the gauze pads, field loss and blood collected in the suction bottle. In all patients the following parameters were monitored,

1) Blood loss at the end of the procedure.

2) Surgical field from the surgeon's point of view every fifteen minutes.

3) Vital signs were monitored preoperatively, intraoperatively - preinduction \& every five minutes after induction and postextubation.

4) Intraoperative adverse events.

Statistical analysis of distribution of sex was done using Chi-Square test. Statistical analysis of age, weight, preop haemoglobin, total blood loss, the surgical field graded according to Fromm's scale, intraoperative heart rate, intraoperative mean arterial pressure and duration of surgery were done using Analysis of variants test [ANOVA test].

\section{Results}

All groups were similar demographically and there was no significant difference with respect to age, sex, weight and pre-operative hemoglobin (Table 2). 
Table 2: Demographic Data

\begin{tabular}{|l|l|l|l|l|l|}
\hline Variable & $\begin{array}{l}\text { Group I } \\
\text { Mean } \pm \text { I SD }\end{array}$ & $\begin{array}{l}\text { Group II } \\
\text { Mean } \pm \text { I SD }\end{array}$ & $\begin{array}{l}\text { Group III } \\
\text { Mean } \pm \text { I SD }\end{array}$ & P Value & SS \\
\hline Age( year $)$ & $34.33 \pm(9.95)$ & $33.8 \pm(7.9)$ & $33.33 \pm(8.79)$ & 0.954 & NS \\
\hline Weight $(\mathrm{kg})$ & $59 \pm(9.66)$ & $63.6 \pm(6.72)$ & $63.73 \pm(8.19)$ & 0.216 & NS \\
\hline Sex M/F & $18 / 12$ & $16 / 14$ & $16 / 14$ & & \\
\hline Preop Hb $(\mathrm{gm} / \mathrm{dl})$ & $12.47 \pm(1.38)$ & $12.06 \pm(1.24)$ & $12.13 \pm(1.22)$ & 0.651 & $\mathrm{NS}$ \\
\hline
\end{tabular}

SS - statistical significance; NS - Insignificant

Table 3: Intra operative hemodynamics

\begin{tabular}{|l|l|l|l|l|l|}
\hline Variable & $\begin{array}{l}\text { Group I } \\
\text { Mean } \pm \text { 1SD }\end{array}$ & $\begin{array}{l}\text { Group II } \\
\text { Mean } \pm \text { 1SD }\end{array}$ & $\begin{array}{l}\text { Group III } \\
\text { Mean } \pm \text { 1SD }\end{array}$ & P - value & SS \\
\hline Heart Rate beats/min & $67 \pm(3.85)$ & $88.9 \pm(5.06)$ & $86.8 \pm(5.7)$ & $<0.001$ & Significant \\
\hline Mean arterial pressure (mm/hg) & $83.47 \pm(4.73)$ & $70.33 \pm(2.26)$ & $98.4 \pm(4.73)$ & $<0.001$ & Significant \\
\hline
\end{tabular}

There was a statistically significant difference in heart rate. Metoprolol, Clonidine and Tranexamic acid group had lesser heart rate as compared to NTG and control group. Mean arterial pressure was lowest in NTG group.

Table 4: Surgical conditions

\begin{tabular}{|l|l|l|l|l|l|}
\hline Variable & $\begin{array}{l}\text { Group I } \\
\text { Mean } \pm \text { 1SD }\end{array}$ & $\begin{array}{l}\text { Group II } \\
\text { Mean } \pm \text { 1SD }\end{array}$ & $\begin{array}{l}\text { Group III } \\
\text { Mean } \pm \text { 1SD }\end{array}$ & P - value & SS \\
\hline Blood Loss (ml) & $318.6 \pm(92.42)$ & $244 \pm(61.04)$ & $422 \pm(61.04)$ & $<0.001$ & Significant \\
\hline Fromm's Score & $3.1 \pm(0.41)$ & $2.3 \pm(0.37)$ & $3.9 \pm(0.36)$ & $<0.001$ & Significant \\
\hline Time (min.) & $74.8 \pm(6.49)$ & $64.4 \pm(4.24)$ & $81.6 \pm(5.92)$ & $<0.001$ & Significant \\
\hline
\end{tabular}

Surgical conditions assessed by blood loss, Fromm's score and duration of surgery were best in Group II. Surgical conditions in Group I was better than control.

\section{Discussion}

Intraoperative bleeding, which reduces visibility in the operative field, is one of the major problems during FESS. The surgeon needs a bloodless field which the anaesthesiologist can achieve by lowering the patient's arterial blood pressure using controlled hypotension ${ }^{5,6,7}$.Complications of hypotensive techniques include reactionary hemorrhage, persistent hypotension, cardiac ischemic injury and loss of vision ${ }^{8}$

Intravenous Nitroglycerin is well known to reduce blood loss and improve surgical field in FESS by inducing hypotension via dilatation of venous capacitance vessels, thus reducing venous return and cardiac output. But reflex tachycardia associated with NTG partially offset the advantage of induced hypotension ${ }^{3,9}$. Beta blockers like Metoprolol, Labetalol and Esmolol were used preoperatively to control the heart rate in view of reducing blood loss ${ }^{10,11,12}$. Clonidine, a centrally acting $\alpha 2$ agonist is not only antihypertensive but has analgesic, sedative, anxiolytic properties. Marchal et al used Clonidine (300 mcg/oral) 90 min prior to surgery to produce a bloodless field in middle ear surgery patients ${ }^{13}$.

Other pharmacological strategies like antifibrinolytic agents (Aprotinin, Tranexamic acid and Aminocaproic acid), Desmopressin, Recombinant factor VIIa have been extensively studied in cardiac, orthopaedic \& liver transplant surgeries and in patients with bleeding diathesis ${ }^{14,15}$. Ahmed et al who studied the effect of Tranexamic acid in endoscopic sinus surgery in children found decreased duration, blood loss and improved intra operative visibility ${ }^{16}$. But none of the studies have compared pre-operative Clonidine, Metoprolol and Tranexamic acid with intravenous Nitroglycerine as hypotensive agents. So, we decided to study the effect of these agents on intraoperative bleeding and visibility of surgical field in FESS in present study.

In our study, we found that the visibility of the operative field was best in Group II when compared to Group I, which is relatively better than control group. The average blood loss was least with Group II averaging $244 \mathrm{ml}$ while in Group I the average blood loss was $318 \mathrm{ml}$ which was less than control group. On comparing the mean intra operative heart rate among the three groups, the mean heart rate was significantly low in Metoprolol, Clonidine and Tranexamic acid group (67 beats/min) than the Nitroglycerin (89beats/min) and control group (87beats/min). Mild hypotension occurred in five patients that responded to intravenous fluid administration. None of the patients had blood loss necessitating blood transfusion.

\section{Conclusion}

From the study result Nitroglycerin infusion appears to have lesser blood loss, better quality of surgical field and reduced duration of surgery compared to premedication with Metoprolol, Clonidine and Tranexamic acid, which is better than normotensive anesthesia in patients undergoing functional endoscopic sinus surgery under general anesthesia. In view of the reported complications of induced hypotension and in conditions where 
Nitroglycerin infusion is contraindicated or not feasible, the use of Metoprolol, clonidine and Tranexamic acid may be an acceptable safer and simpler alternative. However, these study findings could be confirmed and explored further by comparing the hypotensive effects of the study drugs in other patient populations and in the patients undergoing other surgical procedures.

\section{References}

[1]. Josephson JS. Current advances in therapy for sinus disease. Adv.Ther 1992 Jul-Aug; 9(4):255-264

[2]. Teichgraeber JF, Riley WB, Parks DH. Nasal surgery complications. PlastReconstr Surg. 1990; 85:527-31

[3]. Fahmy NR. Nitroglycerin as a hypotensive drug during general anesthesia. Anesthesiology. 1978 Jul; 49(1): 17-20.

[4]. Boezaart AP, van der Merwe J, Coetzee A. Comparison of sodium nitroprusside- and esmolol-induced controlled hypotension for functional endoscopic sinus Surgery. Can J Anaesth. 1995; 42(5 Pt 1):373-376.

[5]. Cincikas D, Ivaskevicius J. Application of controlled arterial hypotension in endoscopic rhino surgery. Medicina (Kaunas). 2003; 39(9):852-9.

[6]. Saitoh K, Suzuki H, Hiruta A et al. Induced hypotension for endoscopic sinus surgery. Masui. 2002 Oct; 51(10): 1100-1103

[7]. Eberhart LH, Folz BJ, Wulf H, Geldner G. Intravenous anaesthesia provides optimal surgical conditions during microscopic and endoscopic sinus surgery.Laryngoscope. 2003 Aug; 113(8):1369-1373.

[8]. Williams E. Postoperative Blindness. Anesthesiol Clin. North America 2002; 20(3): 605-622

[9]. Buniatin AA, Seleznev MN, Flerov EV, Stekol'nikov VV, Grishchenko MN. Controlled hypotension using intravenously administered nitroglycerin during combined general anesthesia and surgery. AnesteziolReanimatol. 1984 Mar-Apr ;( 2): 18-24.

[10]. Nair S, Collins, Hung P, Rees G, Close D, Wormald PJ. The effect of beta-blocker premedication on the surgical field during endoscopic sinus surgery.Laryngoscope 2004 Jun; 114(6): 1042-1046

[11]. U.Srivastava, A.B.Dupargude, D.Kumar, K.Joshi, A.Gupta. Controlled hypotension for Functional Endoscopic Sinus Surgery: Comparison of Esmolol and Nitroglycerine.Indian J Otolaryngology Head Neck Surg. 2013 August; 65(Suppl 2): 440-444

[12]. Poupak Rahimzadeh, Sayed Hamid -Reza Faiz, Mahmoud Reza Alebouyeh. Effects of Premedication with Metoprolol on bleeding and induced hypotension in Nasal surgery.Anesth Pain Med. 2012 winter; 1(3): 157-161

[13]. Marchal JM, Gómez-Luque A, Martos-Crespo F, De La Cuesta Sánchez F, Martínez-López MC, Delgado-Martinez AD. Clonidine decreases intraoperative bleeding in middle ear microsurgery. ActaAnaesthesiol Scand. 2001; 45:627-33

[14]. Porte RJ, Leebeek FW. Pharmacological strategies to decrease transfusion requirements in patients undergoing surgery. Drugs. 2002; 62(15): 2193-2211

[15]. Dunn CJ, Goa KL. Tranexamic acid: a review of its use in surgery and other indications. Drugs. 1999 Jun; 57(6): 1005-1032

[16]. Ahmed A Eldaba, Yasser Mohamed Amr, Osama A Albirmawy. Effects of tranexemic acid during endoscopic sinus surgery in children. Saudi J Anaesth. 2013 Jul-Sep; 7(3): 229-233 